\title{
Research on the carbon emissions of the urban village: a case study of NanTing Village in Guangzhou college town
}

\author{
Zhenqiang $\mathrm{XU}^{\mathrm{a}}$, Dafang $\mathrm{WU}^{\mathrm{b}}$, Shiyin $\mathrm{CHEN}^{\mathrm{c}}$, Shiyun $\mathrm{HE}^{\mathrm{d}}$ and Tao HUANG
}

Institute of Land Resources and Urban-Rural Planning, College of Geographical Sciences, Guangzhou University, Guangzhou 510006, China;

a Author email email: 504631180@qq.com, ${ }^{\mathrm{b}}$ Corresponding author email: wudaf2004@163.com , cemail:921595425@qq.com , 'email:2514805356@qq.com , eemail: 724046917@qq.com.

Key word: Household carbon emissions; Urban Village; NanTing Village; Guangzhou college town Abstract. Guangzhou university city pavilion in the village of micro family activities based on the survey data, based on the method of consumer lifestyle (CLA), through the household survey, questionnaire survey method, using the GIS spatial analysis, research urban village family carbon structure characteristics and the distribution of the per capita carbon emissions in space. The results showed that: The NanTing Village overall carbon emissions, carbon emissions and hydropower accounted for the largest, reaching $77.35 \%$, the family is the most important factor of energy consumption and carbon emission, followed by carbon gas emissions accounted for $20.38 \%$; the worst is the family travel carbon emissions accounted for $2.28 \%$.the household carbon emissions on the main road in the village is relatively more, less; household carbon emissions in the NanTing Village near the University in Northwest carbon emissions, hydropower accounted for the relative ratio of village southeast high.

\section{Introduction}

As is known to all, carbon emission has become a new hot spot of land science research. From the beginning of scholars focus on the macro level such as industrial structure and carbon emissions in the field of industrial production and emission reduction measures to cope with the energy crisis and climate warming, gradually realize that the family is the most important energy consumption sectors. ShonaliPachauri studied the changes in carbon emissions generated by the growth of electricity consumption in India ${ }^{[1]}$.

In recent years, scholars of different emphasis on household carbon emissions, can be roughly divided into the following types: (1) focus on the family energy consumption caused by direct or indirect carbon emissions such as ${ }^{[2]}$, Batih in the study of city household energy consumption shows that lights, televisions, refrigerators and air conditioners is the largest household appliances the electrical energy saving potential ${ }^{[3]}$; (2) from the perspective of family daily consumption of family carbon emissions ${ }^{[4-6]}$, such as lighting, heating and cooling, cooking and hot water, household appliances and personal travel five terminal consumer point of the city and rural residential carbon emission analysis ${ }^{[5]}$. Wenxiu Wang uses the quantitative model of the decomposition of the discovery of oil and electricity consumption are the two main sources of household carbon emissions ${ }^{[6]}$; (3) Comparative Analysis of city and rural household carbon emissions of different features and influencing factors of city ${ }^{[7]}$.(4) impact on household carbon emissions of ${ }^{[8]}$. (5) different family characteristics influence on household carbon emissions of ${ }^{[9-11]}$, such as different family income, family size, age, education level, gender and geographical position, the rebound effect will produce different effects of on household carbon emissions ${ }^{[10]}$.

As the main body of the study of carbon emissions, the city has attracted much attention. On the whole, the domestic and foreign researches on the household carbon emissions focus on the carbon emissions of the city, and lack of the research on the carbon emissions in the villages. However, there are a lot of villages in china. Based on the above analysis, this paper makes a deep investigation on the 
carbon emissions of the villages in the city. Hope to provide the basis and theoretical basis for reducing carbon emissions in villages.

\section{Research regional overview}

XiaoGuWei Street NanTing Village $21 \mathrm{~km}$ from the Panyu District area, 2 kilometers from the XiaoGuWei Street office, Guangdong University of Technology, Academy of Fine Arts and Guangzhou University City, adjacent to Guangdong. Before the construction of Guangzhou University Town, the villagers mainly engaged in agricultural production. After the construction of the University Town, some villagers still stay in situ; some affected by the demolition of the villagers moved to the valley Wai village resettlement. The village is now an area of about 2.16 square kilometers, a population of about more than 3 thousand and 100 people, the floating population of nearly 1000 people. Collective economic income is mainly from the village land contract revenue, the old village idle land, the village is a store and ferry rental income ${ }^{[12]}$.

\section{Methodology and data}

The Model. According to the CLA model, this paper extracted the research focus of our study, through further refine the research content (Figure 1), for evaluation model of this study is as follows. Model, this study was to obtain family characteristics and family low carbon consumer behavior information, on the basis of key research family lived for carbon emissions and transportation of these two aspects of carbon emissions. As shown in the fig. 1.

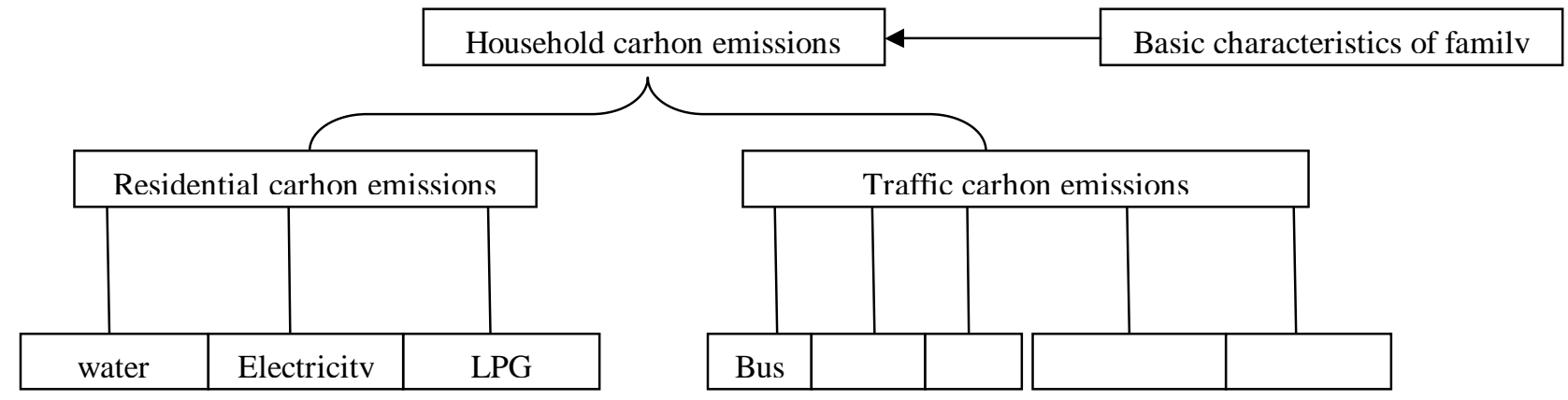

fig. 1 Research model

Data sources. In this paper, the data is in October 2016 through the design of the questionnaire, a questionnaire survey in conjunction with home visits. Questionnaire and research areas of domestic households one-to-one correspondence, point-to-point survey to the domestic carbon emissions space distribution were studied.

On the research content of index data acquisition, basic characteristics, the family of low carbon consumption behavior and the way of transportation directly through questionnaire interview to get the three aspects.

Calculation method. Estimation model based on the family carbon is the IPCC's reference method for the IPCC coefficient method, the apparent consumption of energy, heat energy conversion coefficient, coefficient of carbon oxide and carbon emission factor as the foundation, will affect the family factors of carbon emissions and the corresponding coefficient of carbon emissions, and then calculate the households in the total carbon emissions, to evaluate carbon dioxide emissions. Adopt some general international carbon emissions calculation formula is $\mathrm{C}=\mathrm{AD} * \mathrm{EF}, \mathrm{C}$ for carbon dioxide emissions, $\mathrm{AD}$ for energy consumption, $\mathrm{EF}$ for carbon emissions coefficient (ministry of science and technology, China Taiwan "energy bureau" to determine the release of carbon emissions coefficient). 


\section{Results and discussion}

General Analysis. The household survey and questionnaire we carried out carbon emissions on the South Pavilion Village, distributed a total of 158 questionnaires were recovered in 158, the recovery rate reached $100 \%$, the questionnaire covers the entire South Pavilion Village, high reliability and scientific; after processing the data that 1 households are carbon emissions for $237.21 \mathrm{~kg}$ months, average per capita carbon emissions for $81.17 \mathrm{~kg}$ months. Household carbon emissions in the $1-100 \mathrm{~kg}$ family in the survey of 38 households; emissions in 100-200kg has 46 households; emissions in $200-300 \mathrm{~kg}$ has 24 households; emissions in 300-400kg has 16 households more than 14 households; $400 \mathrm{~kg}$.

According to the data from investigation, NanTing household carbon emission structure household carbon emissions accounted for an important part of hydropower, reached $77.35 \%$, the family is the most important factor of energy consumption and carbon emission, followed by carbon gas emissions accounted for $20.38 \%$; the worst is the family travel carbon emissions accounted for $2.28 \%$. The survey area is located in the University City of the village, has a good subway and traffic lines, the residents are usually in the subway and bus commuters, and subway and bus are relatively low carbon emissions, less, only a few residents have cars and motorcycles, according to the plan, on 120071 the date, in addition to the implementation of the task with the police motorcycles, Guangzhou banned motorcycle driving in urban areas.

Due to lack of natural gas pipeline South Pavilion Village, can only use liquefied petroleum gas filling large carbon emission coefficient; carbon emissions in this area is next to the hydro carbon emissions, but found in the course of our investigation, the family rented South Pavilion Village accounted for more than $1 / 2$, some also is a single room, so a part of the family is not the filling of liquefied petroleum gas, so gas emissions are only hydro carbon emissions, but also far more carbon emissions of hydropower.

Household carbon emissions. Spatial distribution of household carbon emissions (Figure 2). Through the digital processing of the data, obtained as shown in Figure 3, we can see that, because the South Pavilion Village most of the houses have developed into rental housing, access to convenient, perfect rental houses are close to the main road, so the village inside the low carbon emission, carbon emissions near the family trunk on the road is relatively large. Through the main road across the South Pavilion Village, we can divide the village into two main areas, one is the northwest side, close to the University and commercial housing; the other is the southeast, near the University of outer ring road.

(1) The northwest edge of residential apartments closer to the University, the main customers are students, the student apartment is the main single room, they are: the characteristics of carbon emissions of household carbon emissions is relatively concentrated, mainly concentrated in the hydro carbon emissions; due to the approaching school, traffic low carbon emission, gas carbon emission is less, so household carbon emissions is highly concentrated in hydro carbon emissions. Student apartment family population is small, but the per capita carbon emissions is relatively high.

(2) Southeast of Original residential areas is the main customers to work family oriented, so relatively large in the region near the apartment, parking lot, near the bus station, convenient daily work, because it is a working family, produced by the daily life of carbon emissions is large, the most concentrated area and carbon emissions. As shown in the fig. 2. 


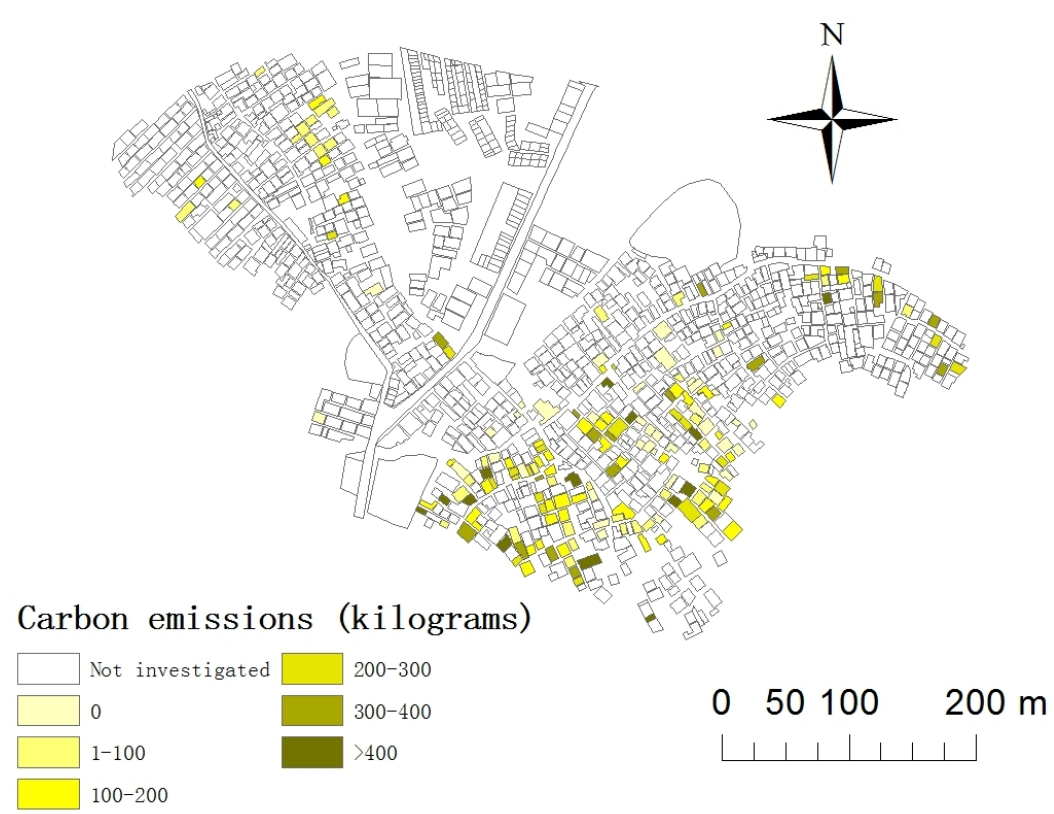

fig. 2 Spatial distribution of carbon emissions in NanTing Village

Notes: White represents investigation area. Including commercial buildings, parking lot, water, roads, and some residential

\section{Conclusions and policy implications}

Household questionnaire survey of household carbon emissions in the NanTing Village during October 2016 and January. The following conclusions are drawn from the analysis: the NanTing Village overall carbon emissions, carbon emissions accounted for the largest hydropower, gas the carbon emissions of carbon emissions from traffic close to the minimum; the household carbon emissions on the main road in the village is relatively more, less; household carbon emissions in the NanTing Village near the northwest, carbon emissions accounted for the hydropower phase than the village of southeast high.

In view of the village population of the South Pavilion activities mainly concentrated in the University City, village residents travel way mainly for electric bicycle, bicycle, bus and subway, only a relatively small number of families have private cars. The use of bicycles will be greatly convenient for residents to travel while reducing household carbon emissions. Therefore, the government made the following recommendations:

(1) Combined with the current in the city of Guangzhou to promote the public bike, suggested that the government improve the management system of public bicycles, to better publicize and promote the use of public bicycles, and improve the construction of University City bike lanes;

(2) Perfect urban transportation planning policy and management standard;

(3) The government should introduce preferential policies to encourage enterprises to household appliances, building materials, energy saving technology innovation; entrepreneurs, energy-saving products to encourage policy;

(4) The government should strengthen the propaganda of low carbon life.

\section{Acknowledgements}

This work was financially supported by the National "Twelfth Five-Year" Plan for Science \& Technology Support(2013BAJ13B01), National Natural Science Foundation of China (41101078), Guangdong education department innovative projects(2014KTSCX090) , Guangdong education scientific research"twelfth five-year" rules Row 2013 annual research project(2013JK134), Guangzhou "twelfth five-year" plan philosophy and social science (15Q28), the quality of undergraduate education and teaching reform project of guangdong province "Real estate 
management" high-quality goods resource sharing class and College students' innovative training at the provincial level in guangdong province department of education Project (201611078086).

\section{References}

[1] Shonali Pachauri, 2014. Household electricity access a trivial contributor to $\mathrm{CO}_{2}$ emissions growth in India. Nature Climate Change, (4): 1073-1076.

[2] Zhaohua Wang, Wei Liu, Jianhua Yin, 2015. Driving forces of indirect carbon emissions from household consumption in China: an input-output decomposition analysis. Natural Hazards, 75: S257-S272. (in Chinese)

[3] Batih H, Sorapipatana C, 2016. Characteristics of urban households' electrical energy consumption in Indonesia and its saving potentials. Renewable and Sustainable Energy Reviews, 57: $1160-1173$.

[4] Hancheng Dai, Toshihiko Masui, Yuzuru Matsuoka, et al, 2012.The impacts of China's household consumption expenditure patterns on energy demand and carbon emissions towards 2050, 50: 736-750.

[5] Jing-Li Fan, Hao Yu, Yi-Ming Wei, 2015. Residential energy-related carbon emissions in urban and rural China during 1996-2012: From the perspective of five end-use activities. Energy and Building, 96: 201-209. (in Chinese)

[6] Wenxiu Wang, Daiqing Zhao, Yaoqiu Kuang, 2016. Decomposition analysis on influence factors of direct household energy-related carbon emission in Guangdong province-Based on extended Kaya identity. Environmental Progress \& Sustainable Energy, 35(1): 298-307. (in Chinese)

[7] Zhen-Hua Feng, Le-Le Zou, Yi-Ming Wei, 2011. The impact of household consumption on energy use and $\mathrm{CO}_{2}$ emissions in China. Energy, 36(1): 656-670. (in Chinese)

[8] Yanmei Li, Rui Zhao, Tianshu Liu, et al, 2015. Does urbanization lead to more direct and indirect household carbon dioxide emissions? Evidence from China during 1996-2012. Cleaner Production, 102: 103-114. (in Chinese)

[9] Liyan Han, Xinkuo Xu, Lu Han, 2015. Applying quantile regression and Shapley decomposition to analyzing the determinants of household embedded carbon emissions: evidence from urban China. Cleaner Production, 103: 219-230. (in Chinese)

[10] J.A. Rosas-Floresa, M.D. Gálvezb, 2010. What goes up: recent trends in Mexican residential energy use. Energy, 35(6): 2596-2602.

[11] Xiaoling Zhang, Lizi Luo, Martin Skitmore, 2015. Household carbon emission research: an analytical review of measurement, influencing factors and mitigation prospects. Cleaner Production, 103: 873-883. (in Chinese)

[12] Yihua Liu, Haolong Chen, Zhangping Lin, Dafang Wu, 2015. The spatial evolution of informal economy and its influence on land use in urban village: A case study of Nanting village in Guangzhou college town. Economic Geography, 35(5): 126-134. (in Chinese) 